\title{
Function of PM2.5 in the pathogenesis of lung cancer and chronic airway inflammatory diseases (Review)
}

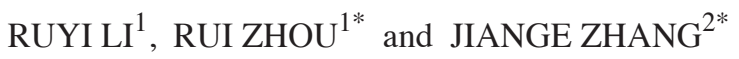 \\ ${ }^{1}$ Department of Respiratory Medicine, The Second Xiangya Hospital, Central South University, \\ Changsha, Hunan 410011; ${ }^{2}$ Innovation Research Institute of Traditional Chinese Medicine, \\ Shanghai University of Traditional Chinese Medicine, Shanghai 201203, P.R. China
}

Received September 18, 2017; Accepted February 28, 2018

DOI: $10.3892 / 01.2018 .8355$

\begin{abstract}
Previous research has identified that air pollution is associated with various respiratory diseases, but few studies have investigated the function served by particulate matter 2.5 (PM2.5) in these diseases. PM2.5 is known to cause epigenetic and microenvironmental alterations in lung cancer, including tumor-associated signaling pathway activation mediated by microRNA dysregulation, DNA methylation, and increased levels of cytokines and inflammatory cells. Autophagy and apoptosis of tumor cells may also be detected in lung cancer associated with PM2.5 exposure. A number of mechanisms are involved in triggering and aggravating asthma and COPD, including PM2.5-induced cytokine release and oxidative stress. The present review is an overview of the underlying molecular mechanisms of PM2.5-induced pathogenesis in lung cancer and chronic airway inflammatory diseases.
\end{abstract}

Correspondence to: Dr Rui Zhou, Department of Respiratory Medicine, The Second Xiangya Hospital, Central South University, 139 Renmin Road, Furong, Changsha, Hunan 410011, P.R. China E-mail: zhourui2355@csu.edu.cn or

Dr Jiange Zhang, Innovation Research Institute of Traditional Chinese Medicine, Shanghai University of Traditional Chinese Medicine, 280 Huatuo Road, Pudong, Shanghai 201203, P.R. China E-mail: jgzhang@shutcm.edu.cn

${ }^{*}$ Contributed equally

Abbreviations: AECOPD, acute exacerbation of chronic obstructive lung disease; COPD, chronic obstructive lung disease; DNMT3B, DNA (cytosine-5-)-methyltransferase $3 \beta$; HBE, human bronchial epithelial; IHD, ischemic heart disease; NSCLC, non-small cell lung cancer

Key words: particulate matter 2.5, pathogenesis, lung cancer, asthma, chronic obstructive lung disease, microRNA, DNA methylation, microenvironment, autophagy, apoptosis, cytokines, oxidative stress

\section{Contents}

1. Introduction

2. PM2.5 has an adverse impact on cardiovascular, respiratory and endocrine systems

3. PM2.5-induced pathogenesis varies in lung cancer

4. PM2.5-induced pathogenesis varies in chronic airway inflammatory diseases

5. PM2.5-induced pathogenesis in lung tuberculosis

6. PM2.5-induced pathogenesis in respiratory infection

7. Conclusions

\section{Introduction}

Previous studies have identified a marked association between particulate matter 2.5 (PM2.5) exposure and increased incidence of pulmonary diseases (1). PM2.5 is a type of air pollutant with a diameter of $\leq 2.5 \mu \mathrm{m}$, characterized by its small particle size (2), large surface area and toxin absorption ability (3). These properties make it possible for PM2.5 to invade the smallest airways, including alveolar tissue. PM2.5 comprises a mixture of solid and liquid particles, including black carbon, metals, nitrate, sulfate, polycyclic aromatic hydrocarbons and automobile exhaust particles (4). It has been demonstrated that exposing mice to PM2.5 led to easier deposition of PM2.5 into lung issues compared with other metal pollutants (5). Numerous biological activities, including cytokine formation, coagulation balance, and cardiac and pulmonary function have been demonstrated to be altered by PM2.5 (6).

It has also been indicated that PM2.5 may trigger asthma, chronic obstructive lung disease (COPD) and lung cancer through the activation of various signaling pathways, including AMP-activated protein kinase (AMPK) catalytic subunit $\alpha 1$ and signal transducer and activator of transcription (STAT)-1 (7). It has also been suggested that vascular endothelial growth factor receptor (VEGF), mitogen-activated protein kinase (MAPK), nuclear factor $\kappa \mathrm{B}(\mathrm{NF}-\kappa \mathrm{B})$ and interleukin (IL)-8 signaling is involved in PM2.5-induced lung injury (8). In PM2.5-exposed rats, a decrease in phosphatidylcholine levels may be detected, which may impair alveolar type II cells and alter cell functions (9). In addition, PM2.5 exposure has been demonstrated to be associated with endothelial cell 
apoptosis and systemic inflammation (10). Numerous studies have suggested that lung function impairment in mice may also be induced by PM2.5 (6), and that the transforming growth factor- $\beta /$ Smad signaling pathway may participate in this process (11). A European cohort study indicated that PM2.5 exposure increased the risk of lung cancer, particularly lung adenocarcinoma (12). Another study demonstrated that if the daily average concentration of PM2.5 was decreased to $10 \mu \mathrm{g} / \mathrm{m}^{3}, 90 \%$ of children with respiratory diseases would be admitted to hospital less frequently (13). Furthermore, each $10-\mu \mathrm{g} / \mathrm{m}^{3}$ increase in PM2.5 was indicated to cause a $0.23 \%$ increase in total emergency room visits due to respiratory diseases, of which the majority of patients exhibited acute exacerbation of COPD (AECOPD). The rate of respiratory infection has also been demonstrated to increase with increased PM2.5 levels (14). Similar results were obtained in terms of hospital admissions of respiratory diseases and PM2.5 levels in Taiwan (15). Furthermore, it has been revealed that the mortality rates of emphysema, asthma and pneumonia are significantly associated with particulate polluting matter (16). PM2.5 has also been positively associated with the number of outpatient visits for acute respiratory diseases, including acute bronchitis (17).

\section{PM2.5 has an adverse impact on cardiovascular, respiratory and endocrine systems}

A considerable number of epidemiological studies have demonstrated that long-term exposure to PM2.5 may cause damage to the cardiovascular, respiratory and endocrine systems $(18,19)$. It has been indicated that PM2.5 exposure is associated with a notable proportion of mortalities due to numerous diseases, including lung cancer (23.9\%), COPD $(18.7 \%)$, stroke $(40.3 \%)$ and ischemic heart disease (IHD) (26.8\%) (20). It was reported that each $10-\mu \mathrm{g} / \mathrm{m}^{3}$ increase in acute PM2.5 exposure in the northeastern USA resulted in a $0.26 \%$ increase in the number of admissions of patients with peripheral artery disease (21). Similarly, in Beijing (China), PM2.5 was significantly associated with the number of hospital emergency room visits for cardiovascular diseases, particularly IHD, heart arrhythmia and atrial fibrillation (22). PM2.5 exposure together with cigarette smoking has been demonstrated to have an even greater impact on cardiovascular disease-associated mortality (23). A meta-analysis study indicated that ambient PM2.5 exposure was associated with a high risk of atrial fibrillation (24). However, it has been reported that lung cancer and cardiovascular diseases respond differently to PM2.5 exposure (25).

In terms of endocrine function, it has been suggested that early-life PM2.5 exposure may serve a pivotal effect in childhood overweight or obesity (26). Another study detected impairment of adult renal function in the Taipei metropolis following exposure to PM10, but not PM2.5 (27).

\section{PM2.5-induced pathogenesis varies in lung cancer}

Epidemiological studies of lung cancer. Researchers have identified lung cancer as one of the most significant causes of cancer-associated mortality, and non-small cell lung cancer (NSCLC) has been reported to account for $80 \%$ lung cancer (28). NSCLC has a low 5-year survival rate (29). Previous epidemiological studies have indicated that ambient PM2.5 is carcinogenic (30), and may increase the morbidity and mortality rates associated with lung cancer $(31,32)$, and PM2.5 has been suggested to decrease the survival time of patients with lung cancer (33). A short-term decrease in PM2.5 exposure has been demonstrated to decrease the population risk of lung cancer (34).

Oncogene activation, mediated by microRNAs (miRs), involved in PM2.5-induced lung cancer. miRs are a class of small non-coding single-stranded RNA molecules which participate in the regulation of post-transcriptional gene expression and RNA silencing (35). It has been established that miRs regulate $50 \%$ of protein-coding genes and cell metabolic processes (36). However, the pathogenesis of PM2.5 induction of lung cancer remains to be elucidated. A previous study indicated that exposing human bronchial epithelial (HBE) cells to ambient PM2.5 resulted in downregulation of miR-182 and miR-185 expression compared with non-exposed cells (37). The expression of three target oncogenes, solute carrier family 30 member 1 , serpin family $\mathrm{B}$ member 2 and aldo-keto reductase family 1 member $\mathrm{C} 1$, which are markedly expressed in human lung adenocarcinoma cells and squamous carcinoma cells, may cause neoplastic transformation in NIH3T3 cells (37). However, whether this is translatable to humans remains unknown. Another study investigated the association between PM2.5 exposure and the miR-802/Rho family GTPase 3 (Rnd3) pathway in lung cancer in vivo and in vitro. PM2.5 was demonstrated to enhance the growth and metastasis of lung cancer (38). These results warrant further investigation of PM2.5-induced miR changes in lung cancer.

PM2.5-induced gene mutations have been investigated extensively. In one study, following exposure of HBE cells to 200 and $500 \mu \mathrm{g} / \mathrm{ml} \mathrm{PM} 2.5,970$ and 492 gene alterations were detected, respectively (39). Furthermore, an in vivo study demonstrated that, in PM2.5-treated mice, 57 genes were demonstrated to be mutated, including 14 upregulated genes and 43 downregulated genes (40). It has been suggested that these mutations occur in response to an exogenous stimulus, metabolic processing and an inflammatory immune pathway, possibly involving the MAPK signaling pathway (41). These studies provide a preliminary basis to direct further investigation of the function of miRs in oncogene activation in lung cancer following PM2.5 exposure. Furthermore, the interaction between PM2.5-induced long non-coding RNA (lncRNA) alteration and lung cancer has been studied, indicating that PM2.5 is able to induce lncRNA loc146880 via reactive oxygen species (ROS), promoting autophagy and malignancy of lung cancer cells (42).

PM2.5-induced tumor suppressor gene inactivation through DNA methylation. p53 is an important regulatory gene in cell proliferation, apoptosis and damage repair (43). Mutation of p53 contributes to the pathogenesis of lung cancer $(44,45)$. A previous study sought to identify PM2.5-induced p53 mutations using human alveolar epithelial BEAS-2B cells constantly exposed to low-dose PM2.5 for 10 days. It was demonstrated that PM2.5 was able to trigger p53 promoter 
methylation by increasing DNA (cytosine-5-)-methyltransferase $3 \beta$ (DNMT3B) methylation levels, resulting in p53 inactivation. The same study indicated that the ROS/protein kinase B (Akt) signaling pathway was involved in the process of DNMT3B methylation (46). Notably, these cells were exposed long term to 'safe' concentrations of PM2.5 $\left(120 \mu \mathrm{g} / \mathrm{m}^{3}\right)$. Furthermore, a previous study established that the expression of DNMT was different when cells were acutely exposed to high-dose PM2.5 (data not shown) (46). To the best of our knowledge, inactivation of other PM2.5-induced tumor suppressor genes via DNA methylation has not been demonstrated. However, a recent analysis of the methylome and transcriptome of PM2.5-induced $(100 \mu \mathrm{g} / \mathrm{ml})$ BEAS-2B cells identified 66 differentially expressed genes, which were either hyper- or hypo-methylated, involved in lung diseases, particularly lung cancer (47). A number of the genes were identified to be involved in tumor suppression, including deleted in malignant brain tumors 1, ERBB receptor feedback inhibitor 1 and gap junction protein $\beta 2$. Another study observed gene methylation in healthy mice exposed to traffic-associated air pollution, including upregulation of p16 and adenomatous polyposis coli methylation, and downregulation of long interspersed nuclear element- 1 and nitric oxide synthase 2 methylation (48). It has been demonstrated that following exposure to PM2.5, DNA methylation of tandem repeats increases (49). A tandem repeat (NBL2) methylation has been identified to be associated with PM2.5 silicon in truck drivers, and another tandem repeat (SAT $\alpha$ ) methylation has been associated with sulfur exposure in office workers (50), which may lead to an increase in the risk of lung cancer. These studies provide a basis for further investigation of the association between PM2.5-induced tumor suppressor gene methylation and lung cancer.

PM2.5-induced microenvironment alteration in lung cancer. The tumor microenvironment is of importance to tumor behavior, particularly in lung cancer (51). The production of cytokines, inflammatory cells and angiogenesis has been identified to be associated with tumor metastasis and tumor cell proliferation (52). Numerous inflammatory cytokines and transcription factors function in the lung cancer tumor microenvironment, including interleukin (IL)-1 $\beta$ and -6 , tumor necrosis factor $\alpha$ (TNF- $\alpha$ ), NF- $\mathrm{kB}$ and STAT-3 (53). PM2.5 exposure is able to increase the mobility and proliferation of A549 and H1299 cells, and IL-1 $\beta$ and MMP-1 may be responsible for the effects of PM2.5 (54). It has also been suggested that alveolar macrophage polarization may serve a function in angiogenesis and tumor growth via secretion of IL-8 and VEGF (55). Previous studies have demonstrated that PM2.5 is able to induce HBE cells and macrophages to release various pro-inflammatory cytokines, including IL-6, TNF- $\alpha$ and granulocyte-macrophage colony stimulating factor (GM-CSF), resulting in airway inflammation $(41,56,57)$. Therefore, by triggering angiogenesis and inflammatory reactions, PM2.5-induced tumor microenvironment alteration may promote tumor growth and metastasis.

PM2.5-induced autophagy and apoptosis. Autophagy refers to the encapsulation of damaged proteins or organelles of eukaryotic cells by autophagic vesicles, followed by lysosomal degradation and recycling (58). Autophagy serves an important function in emergent cell processes, including starvation and infection (59). As a self-destructive activity, apoptosis serves an essential function in tissue homeostasis, embryonic development and organogenesis (60). Crosstalk between autophagic and apoptotic pathways have been characterized in cell fate decision making $(61,62)$. Caspases, a group of cysteine proteases, are best known as apoptosis modulators, and function in the crosstalk between autophagy and apoptosis (63). Crucial autophagy proteins, including Beclin-1 and autophagy-related 5 may be degraded by activated caspases to attenuate the autophagic response $(64,65)$. Furthermore, autophagy is able to regulate apoptosis by altering the level and activity of caspase proteins (66). PM2.5 exposure may induce macrophage autophagy and mediate the Src/STAT-3 signaling pathway to increase the expression of VEGF-A, an important pro-angiogenic factor (67). It has also been suggested that the phosphoinositide 3-kinase/Akt/mechanistic target of rapamycin kinase signaling pathway may serve an important function in the autophagy of BEAS-2B cells exposed to PM2.5 (68). PM2.5 is able to induce autophagy of A549 cells by activating the AMPK signaling pathway (69). Autophagy serves as a protective mechanism, thus preventing further damage by PM2.5 (70).

PM2.5 induces inflammatory cell infiltration and alveolar cell autophagy, and also alters the cell cycle of alveolar epithelial cells and induces cell apoptosis. A number of studies have demonstrated that PM2.5 is able to induce mitotic arrest by breaking DNA double strands and activating the p53/retinoblastoma signaling pathway (71-73). PM2.5 has also been demonstrated to activate the TNF- $\alpha$ signaling pathway and manipulate the transcription of p53, B-cell lymphoma 2 (Bcl-2) and $\mathrm{Bcl}-2$-associated $\mathrm{X}$ protein, resulting in apoptosis of alveolar epithelial cells $(74,75)$.

\section{PM2.5-induced pathogenesis varies in chronic airway inflammatory diseases}

Epidemiological investigation of chronic airway inflammatory diseases. The most common chronic airway inflammatory diseases are asthma and COPD (76). Asthma is characterized by chronic pulmonary inflammation and airway hyper-responsiveness (77). It has been demonstrated that asthma is associated with numerous environmental and genetic factors (78). Epidemiological evidence suggests that air pollution, including ambient PM2.5, may increase the morbidity and hospitalization rate of patients with asthma (79-81). Furthermore, air pollution has become an independent risk factor of asthma (82). Increased PM10 exposure has been identified to be associated with poor control of asthma and poor health-associated quality of life (83). The airway inflammation and immune response in the pathogenesis of asthma have been identified to be associated with the chemical composition and size distribution of PM2.5 (84). It has been identified that with increased levels of the heavy metal lead in PM2.5 in e-waste recycling areas, the level of lead in pediatric blood samples also increased (85). This is a cause for concern since asthma may be induced when blood lead content $>5 \mu \mathrm{g} / \mathrm{dl}(85)$. 


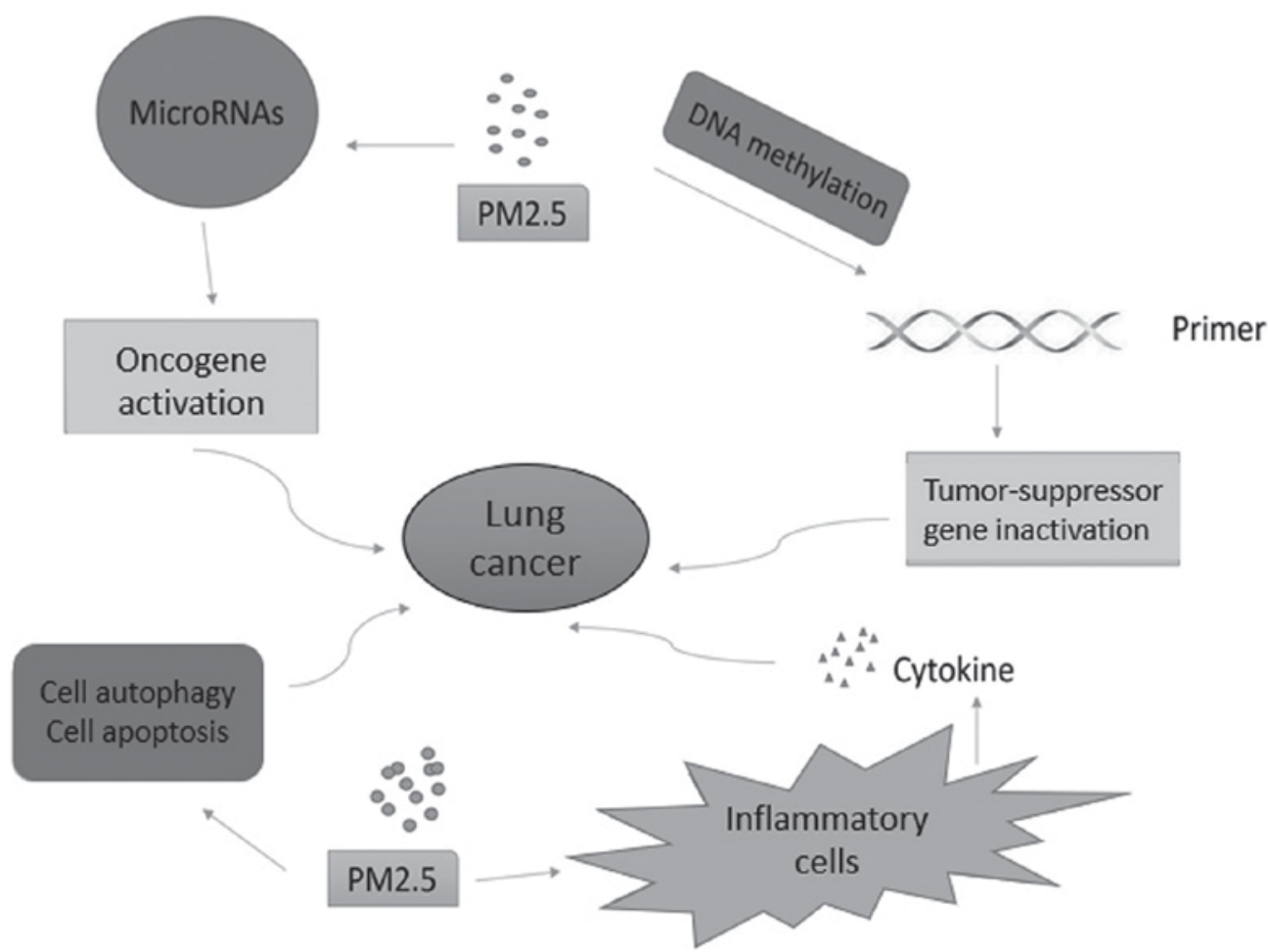

Figure 1. Function of PM2.5 in the pathogenesis of lung cancer. PM2.5 induces oncogene activation and tumor suppressor gene inactivation through microRNA dysregulation and DNA methylation in lung cancer. Tumor microenvironment alteration is also detected in PM2.5-induced inflammatory cells. PM2.5, particulate matter 2.5 .
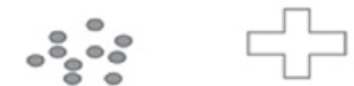

PM2.5
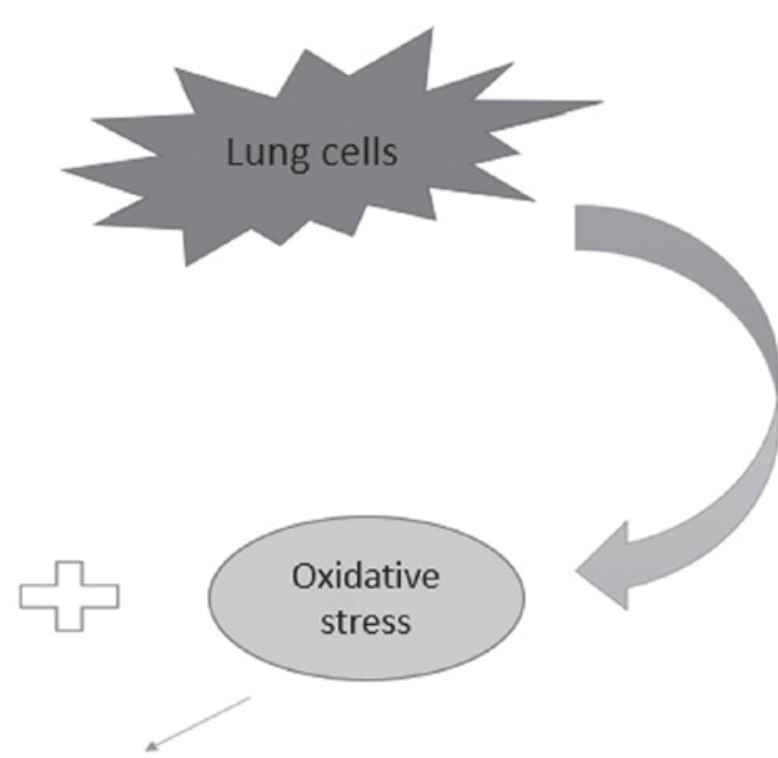
expression

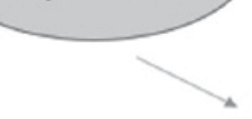

\section{Chronic airway inflammatory}

diseases

Figure 2. Function of PM2.5 in the pathogenesis of chronic airway inflammatory diseases. PM2.5 affects normal lung cells in chronic airway inflammatory diseases by affecting cytokine expression and oxidative stress. PM2.5, particulate matter 2.5.

COPD is a type of obstructive lung disease characterized by long-term poor airflow, which typically worsens over time (86). Numerous studies have demonstrated that AECOPD is associated with air pollution, particularly PM2.5 (87). Each additional $10 \mu \mathrm{g} / \mathrm{m}^{3} \mathrm{PM} 2.5$ exposure has been demonstrated to increase the rate of coughing symptoms by $33 \%$ and expectoration symptoms by $23 \%$, and to decrease the diurnal variation rate of peak expiratory flow in patients with COPD (88). Long-term exposure to PM2.5 has been demonstrated to decrease the population forced expiratory volume in $1 \mathrm{sec}$ 
and the forced vital capacity, accelerating the decline in lung function in healthy adults in a population-based cohort (89). Therefore, preventive medication is required to avoid exacerbation of COPD following exposure to PM2.5 (90).

PM2.5-induced inflammatory response and oxidative stress. Oxidative stress is able to modulate critical signal transduction pathways, including NF- $\mathrm{KB}$ signaling, and histone modifications; alterations which are crucial in lung inflammation (91). PM2.5 has been demonstrated to increase the expression of inflammatory cytokine receptors, which are able to activate IL-1 receptor (IL-1R)- and IL-6R-mediated signaling pathways in cells of the lung (92). In a previous study, short-term exposure of PM2.5 to mice induced inflammatory cell infiltration and lung tissue congestion, increasing the expression of inflammatory mediators, including TNF- $\alpha$, IL- 6 and IL-1 $\beta$, and oncogenes, including c-Fos and c-Jun, which dysregulated a variety of metabolic enzyme activities, including superoxide dismutase and nitric oxide synthase (93). It has been reported that lung oxidative stress and inflammation may be induced by a low dose of PM2.5 in healthy mice (94).

PM2.5 has been demonstrated to increase the level of NF-E2-related factor 2 (Nrf2) expression in mice with COPD, and Nrf2 was associated with oxidative stress (95). PM2.5 exposure was observed to increase the expression of IL-8 in vitro, which was mediated by oxidative stress and endocytosis (96). The enhanced expression of TNF- $\alpha$ and IL-6 has also been detected in sub-chronic (PM2.5 tracheal instillation once a week for 1, 3 or 6 months) PM2.5-exposed mice with COPD, and it is known that cytokine overexpression is able to aggravate immune system damage (97).

Sub-chronic exposure to PM2.5 has also been indicated to induce inflammatory injury in rats and impair the phagocytic function of AM (alveolar macrophage) (98). Furthermore, PM2.5 has been demonstrated to increase the phagocytic ability of macrophages in mice with COPD, thus increasing oxidative stress (99). PM2.5 also impairs the immune balance of mice with COPD by blocking the Notch signaling pathway (99). Exposing nasal mucosa epithelial cells to PM2.5 indicated that PM2.5 was able to increase ROS and Nrf2 levels, which have an association with oxidative stress (100). This study also revealed that PM2.5 increased the release of GM-CSF, TNF- $\alpha$ and IL-13, accelerating the inflammatory reaction. Previous research has revealed that the process of inflammation and oxidative stress occur via different pathways (101), and different PM sources may result in different ROS viabilities (102). In order to explore the function of PM2.5 in the pathogenesis of asthma, one research group exposed asthmatic mice to PM2.5, revealing that the content of IL- 4 and IL-10, mediated by TNF- $\alpha$ and T helper 2 cells, increased, coupled with the decreased content of INF- $\gamma$ mediated by $\mathrm{T}$ helper 1 cells. Inflammatory infiltration and goblet cell metaplasia were also demonstrated to be accelerated following PM2.5 exposure (103). The acute inflammatory response following PM2.5 exposure has been revealed to involve TLR2 and TLR4, and a T helper 2 cell-mediated immune response was also detected (104). Furthermore, PM was demonstrated to induce $\mathrm{T}$ helper $1 / 2$ cell inflammatory responses in healthy mice and may contribute to the initial onset of asthma (105).

\section{PM2.5-induced pathogenesis in lung tuberculosis}

Tuberculosis is a common chronic infectious disease caused by Mycobacterium tuberculosis, which is able to invade multiple organs, including the lungs (106). However, few studies have investigated the association between PM2.5 and pulmonary tuberculosis. It has been demonstrated that PM2.5 exposure in factory environments and smear-positive tuberculosis are associated; however, PM2.5 exposure in highway environments and smear-positive tuberculosis were not associated (107). PM2.5 exposure has been suggested to decrease the expression of hemoglobin subunit $\mathrm{d} 2$ and 3 in type II alveolar epithelial cells, increasing the risk of M. tuberculosis proliferation (108).

\section{PM2.5-induced pathogenesis in respiratory infection}

Respiratory infection may be characterized into upper and lower respiratory tract infections (109). It has been revealed that air pollution PM may alter anti-mycobacterial respiratory epithelium innate immunity systems (110). A European cohort study demonstrated that early childhood pneumonia was associated with air pollutants (111). Another study suggested that organic compounds in PM2.5 are able to aggravate the infection of upper and lower respiratory tract infections in children (112). It has also been indicated that the DNA repair gene xeroderma pigmentosum complementation group $\mathrm{C}$ may serve an essential function in the pathogenesis of PM2.5-induced bronchitis (113). To the best of our knowledge, the effect of PM2.5 in respiratory infection has not been demonstrated.

\section{Conclusions}

From the present review, the following conclusions can be inferred. The chemical properties and pathological toxicity of PM2.5 are known to influence a variety of respiratory diseases. Previous research has focused on the epidemiology and toxicology of PM2.5; however, more recent research has investigated the function that PM2.5 serves in the pathogenesis of respiratory diseases. PM2.5-induced epigenetic changes, including microRNA dysregulation (37) and DNA methylation (46), microenvironment alteration (53), cell autophagy and apoptosis $(67,68)$, may result in oncogene activation and tumor suppressor gene inactivation in lung cancer (Fig. 1). By activating inflammatory-associated cells (93), including $\mathrm{T}$ helper 2 cells, and triggering oxidative stress (97), PM2.5 may induce and aggravate asthma and COPD (Fig. 2). PM2.5-induced alteration of molecular mechanisms in pulmonary tuberculosis and respiratory infection remain unclear. Furthermore, the properties of PM2.5 often vary with environmental changes, and further clarification is required.

Investigating the impact of PM2.5 on respiratory disease is essential, since numerous populations are currently experiencing heavy pollution. Understanding the molecular mechanisms of PM2.5-induced respiratory diseases may 
contribute to the development of targeted drugs and preventive treatments.

\section{Acknowledgements}

Not applicable.

\section{Funding}

The present study was supported by the National Key Clinical Specialty Construction Projects of China and National Natural Science Foundation of China (grant no. 81573579).

\section{Availability of data and materials}

Not applicable.

\section{Authors' contributions}

RL was responsible for the acquisition, analysis and summarizing of data, drafting the manuscript and revising it. RZ was involved in analyzing and interpreting the manuscript, and giving final approval of the version to be published. JZ has made substantial contributions to the conception and design of the present study. RZ and JZ are accountable for all aspects of the work.

\section{Ethics approval and consent to participate}

Not applicable.

\section{Consent for publication}

Not applicable.

\section{Competing interests}

The authors declare that they have no competing interests.

\section{References}

1. Li P, Xin J, Wang Y, Wang S, Li G, Pan X, Liu Z and Wang L: The acute effects of fine particles on respiratory mortality and morbidity in Beijing, 2004-2009. Environ Sci Pollut Res Int 20: 6433-6444, 2013.

2. Du P, Du R, Ren W, Lu Z and Fu P: Seasonal variation characteristic of inhalable microbial communities in PM2.5 in Beijing city, China. Sci Total Environ 610-611: 308-315, 2018.

3. Kim Y, Seo J, Kim JY, Lee JY, Kim H and Kim BM Characterization of PM2.5 and identification of transported secondary and biomass burning contribution in Seoul, Korea. Environ Sci Pollut Res Int 25: 4330-4343, 2018.

4. Bell ML, Dominici F, Ebisu K, Zeger SL and Samet JM: Spatial and Temporal Variation in PM2.5 Chemical Composition in the United States for Health Effects Studies. Environ Health Perspect 115: 989-995, 2007.

5. Li Q, Liu H, Alattar M, Jiang S, Han J, Ma Y and Jiang C: The preferential accumulation of heavy metals in different tissues following frequent respiratory exposure to PM2.5 in rats. Sci Rep 5: 16936, 2015.

6. Jiang S, Bo L, Du X, Liu J, Zeng X, He G, Sun Q, Kan H, Song W, Xie Y and Zhao J: CARD9-mediated ambient PM 2.5-induced pulmonary injury is associated with Th17 cell. Toxicol Lett 273: 36-43, 2017.

7. Falcon-Rodriguez CI, Osornio-Vargas AR, Sada-Ovalle I and Segura-Medina P: Aeroparticles, composition, and lung diseases. Front Immunol 7: 3, 2016.
8. Jeong SC, Cho Y, Song MK, Lee E and Ryu JC: Epidermal growth factor receptor (EGFR)-MAPK-nuclear factor(NF)- $\mathrm{BB}-\mathrm{IL} 8$ : A possible mechanism of particulate matter(PM) 2.5-induced lung toxicity. Environ Toxicol 32: 1628-1636, 2017.

9. Chen WL, Lin CY, Yan YH, Cheng KT and Cheng TJ: Alterations in rat pulmonary phosphatidylcholines after chronic exposure to ambient fine particulate matter. Mol Biosyst 10: 3163-3169, 2014.

10. Pope CA III, Bhatnagar A, Mccracken JP, Abplanalp W, Conklin DJ and O'Toole T: Exposure to fine particulate air pollution is associated with endothelial injury and systemic inflammation. Circ Res 119: 1204, 2016.

11. Gu LZ, Sun H and Chen JH: Histone deacetylases 3 deletion restrains PM2.5-induced mice lung injury by regulating $\mathrm{NF}-\kappa \mathrm{B}$ and TGF- $\beta / \mathrm{Smad} 2 / 3$ signaling pathways. Biomed Pharmacother 85: 756-762, 2017.

12. Raaschou-Nielsen O, Andersen ZJ, Beelen R, Samoli E, Stafoggia M, Weinmayr G, Hoffmann B, Fischer P, Nieuwenhuijsen MJ, Brunekreef B, et al: Air pollution and lung cancer incidence in 17 European cohorts: Prospective analyses from the European Study of Cohorts for Air Pollution Effects (ESCAPE). Lancet Oncol 14: 813-822, 2013.

13. deP Pablo-Romero M,Román R,Limón JM and Praena-Crespo M: Effects of fine particles on children's hospital admissions for respiratory health in Seville, Spain. J Air Waste Manage Assoc 65: 436-444, 2015.

14. Xu Q, Wang S, Guo Y, Wang C, Huang F, Li X, Gao Q, Wu L, Tao L, Guo J, et al: Acute exposure to fine particulate matter and cardiovascular hospital emergency room visits in Beijing, China. Environ Pollut 220: 317-327, 2017.

15. Tsai SS, Chiu HF, Liou SH and Yang CY: Short-term effects of fine particulate air pollution on hospital admissions for respiratory diseases: A case-crossover study in a tropical city. J Toxicol Environ Health A 77: 1091-1101, 2014.

16. Kravchenko J, Akushevich I, Abernethy AP, Ross WG Jr and Lyerly HK: Long-term dynamics of death rates of emphysema, asthma, and pneumonia and improving air quality. Int J Chron Obstruct Pulmon Dis 9: 613-627, 2014.

17. Li R, Jiang N, Liu Q, Huang J, Guo X, Liu F and Gao Z: Impact of air pollutants on outpatient visits for acute respiratory outcomes. Int J Environ Res Public Health 14: pii:E47, 2017.

18. Lin H, Wang X, Liu T, Li X, Xiao J, Zeng W and Ma W: Air Pollution and Mortality in China. Adv Exp Med Biol 1017: 103-121, 2017.

19. Vahedian M, Khanjani N, Mirzaee M and Koolivand A: Ambient air pollution and daily hospital admissions for cardiovascular diseases in Arak, Iran. ARYA Atheroscler 13: 117-134, 2017.

20. Song C, He J, Wu L, Jin T, Chen X, Li R, Ren P, Zhang L and Mao H: Health burden attributable to ambient PM2.5 in China. Environ Pollut 223: 575-586, 2017.

21. Kloog I: Fine particulate matter (PM2.5) association with peripheral artery disease admissions in northeastern United States. Int J Environ Health Res 26: 572-577, 2016.

22. Qin X, Xia L, Wang S, Chao W, Huang F, Qi G, Wu L, Tao L, Jin $G$ and Wei W: Fine particulate air pollution and hospital emergency room visits for respiratory disease in Urban areas in Beijing, China, in 2013. PLoS One 11: e0153099, 2016.

23. Turner MC, Cohen A, Burnett RT, Jerrett M, Diver WR, Gapstur SM, Krewski D, Samet JM and Pope CA III: Interactions between cigarette smoking and ambient PM2.5 for cardiovascular mortality. Environ Res 154: 304-310, 2017.

24. Shao Q, Liu T, Korantzopoulos P, Zhang Z, Zhao J and Li G: Association between air pollution and development of atrial fibrillation: A meta-analysis of observational studies. Heart Lung 45: 557-562, 2016.

25. Pope CA III, Burnett RT, Turner MC, Cohen A, Krewski D, Jerrett M, Gapstur SM and Thun MJ: Lung cancer and cardiovascular disease mortality associated with ambient air pollution and cigarette smoke: Shape of the exposure-response relationships. Environ Health Perspect 119: 1616-1621, 2011.

26. Mao G, Nachman RM, Sun Q, Zhang X, Koehler K, Chen Z, Hong X, Wang G, Caruso D and Zong G: Individual and Joint Effects of Early-Life Ambient PM2.5 Exposure and Maternal Pre-Pregnancy Obesity on Childhood Overweight or Obesity. Environ Health Perspect, 2016.

27. Yang YR, Chen YM, Chen SY and Chan CC: Associations between long-term particulate matter exposure and adult renal function in the taipei metropolis. Environ Health Perspect 125: 602-607, 2017. 
28. Ramalingam S, Pawlish K, Gadgeel S, Demers R and Kalemkerian GP: Lung cancer in young patients: Analysis of a Surveillance, Epidemiology, and End Results database. J Clin Oncol 16: 651-657, 1998.

29. Wang N, Liang H, Zhou Y, Wang C, Zhang S, Pan Y, Wang Y, Yan X, Zhang J, Zhang CY, et al: miR-203 suppresses the proliferation and migration and promotes the apoptosis of lung cancer cells by targeting SRC. PLoS One 9: e105570, 2014.

30. Harrison RM, Smith DJ and Kibble AJ: What Is Responsible for the Carcinogenicity of PM2.5? Occup Environ Med 61: 799-805, 2004.

31. Li J, Li WX, Bai C and Song Y: Particulate matter-induced epigenetic changes and lung cancer. Clin Respir J 11: 539-546, 2017.

32. Vinikoor-Imler LC, Allen DJ and Luben TJ: An ecologic analysis of county-level PM2.5 concentrations and lung cancer incidence and mortality. Int J Environ Res Public Health 8: 1865-1671, 2011.

33. Eckel SP, Cockburn M, Shu YH, Deng H, Lurmann FW, Liu L and Gilliland FD: Air pollution affects lung cancer survival. Thorax 71: 891-898, 2016.

34. Xie Y, Zhao B, Zhao Y, Luo Q, Wang S, Zhao B and Bai S: Reduction in population exposure to PM2.5 and cancer risk due to PM2.5-bound PAHs exposure in Beijing, China during the APEC meeting. Environ Pollut 225: 338-345, 2017.

35. Fabian MR, Sonenberg N and Filipowicz W: Regulation of mRNA translation and stability by microRNAs. Annu Rev Biochem 79: 351-379, 2010.

36. Papoutsidakis N, Deftereos S, Kaoukis A, Bouras G, Giannopoulos G, Theodorakis A, Angelidis C, Hatzis G and Stefanadis C: MicroRNAs and the heart: Small things do matter. Curr Top Med Chem 13: 216-230, 2013.

37. Liu C, Guo H, Cheng X, Shao M, Wu C, Wang S, Li H, Wei L, Gao Y, Tan W, et al: Exposure to airborne PM2.5 suppresses microRNA expression and deregulates target oncogenes that cause neoplastic transformation in NIH3T3 cells. Oncotarget 6: 29428-29439, 2015.

38. Li X, Lv Y, Gao N, Sun H, Lu R, Yang H, Zhang C, Meng Q, Wu S, Li AQ, et al: microRNA-802/Rnd3 pathway imposes on carcinogenesis and metastasis of fine particulate matter exposure. Oncotarget 7: 35026-35043, 2016.

39. Ding X, Wang M, Chu H, Chu M, Na T, Wen Y, Wu D, Han B, Bai Z, Chen W, et al: Global gene expression profiling of human bronchial epithelial cells exposed to airborne fine particulate matter collected from Wuhan, China. Toxicol Lett 228: 25-33, 2014.

40. Sancini G, Farina F, Battaglia C, Cifola I, Mangano E, Mantecca P, Camatini M and Palestini P: Health risk assessment for air pollutants: Alterations in lung and cardiac gene expression in mice exposed to Milano winter fine particulate matter (PM2.5). PLoS One 9: e109685, 2014.

41. Zhou Z, Liu Y, Duan F, Qin M, Wu F, Sheng W, Yang L, Liu J and He K: Transcriptomic analyses of the biological effects of airborne PM2.5 exposure on human bronchial epithelial cells. PLoS One 10: e0138267, 2015.

42. Deng X, Feng N, Zheng M, Ye X, Lin H, Yu X, Gan Z, Fang Z, Zhang H, Gao M, et al: PM 2.5 exposure-induced autophagy is mediated by lncRNA loc146880 which also promotes the migration and invasion of lung cancer cells. Biochim Biophys Acta 1861: 112-125, 2017

43. Cai W, Li Q, Yang Z, Miao X, Wen Y, Huang S and Ouyang J: Expression of p53 upregulated modulator of apoptosis (PUMA) and $\mathrm{C}$-myb in gallbladder adenocarcinoma and their pathological significance. Clin Transl Oncol 15: 818-824, 2013.

44. Ellis P, Lonning PE, Borresen-Dale A, Aas T, Geisler S, Akslen LA, Salter I, Smith IE and Dowsett M: Absence of p21 expression is associated with abnormal p53 in human breast carcinomas. Br J Cancer 76: 480-485, 1997.

45. Deben C, Van den Bossche J, Van Der Steen N, Lardon F, Wouters A, de Beeck KO, Hermans C, Jacobs J, Peeters M, Van Camp G, et al: Deep sequencing of the TP53 gene reveals a potential risk allele for non-small cell lung cancer and supports the negative prognostic value of TP53 variants. Tumour Biol 39: 1010428317694327, 2017

46. Zhou W, Tian D, He J, Wang Y, Zhang L, Cui L, Jia L, Zhang L, Li L, Shu Y, et al: Repeated PM2.5 exposure inhibits BEAS-2B cell P53 expression through ROS-Akt-DNMT3B pathway-mediated promoter hypermethylation. Oncotarget 7: 20691-20703, 2016.

47. Heßelbach K, Kim GJ, Flemming S, Häupl T, Bonin M, Dornhof R, Günther S, Merfort I and Humar M: Disease relevant modifications of the methylome and transcriptome by particulate matter (PM2.5) from biomass combustion. Epigenetics 12: 779-792, 2017
48. Ding R, Jin Y, Liu X, Zhu Z, Zhang Y, Wang T and Xu Y: Characteristics of DNA methylation changes induced by traffic-related air pollution. Mutat Res Genet Toxicol Environ Mutagen 796: 46-53, 2016.

49. Guo L, Byun HM, Zhong J, Motta V, Barupal J, Zheng Y, Dou C, Zhang F, Mccracken JP, Diaz A, et al: Effects of short-term exposure to inhalable particulate matter on DNA methylation of tandem repeats. Environ Mol Mutagen 55: 322-335, 2014.

50. Hou L, Zhang X, Zheng Y, Wang S, Dou C, Guo L, Byun HM, Motta V, Mccracken J, Díaz A, et al: Altered methylation in tandem repeat element and elemental component levels in inhalable air particles. Environ Mol Mutagen 55: 256-265, 2014.

51. Graves EE, Maity A and Le QT: The tumor microenvironment in non-small cell lung cancer. Semin Radiat Oncol 20: 156-163, 2010.

52. Vendramini-Costa DB and Carvalho JE: Molecular link mechanisms between inflammation and cancer. Curr Pharm Des 18 $3831,2012$.

53. Cho WC, Kwan CK, Yau S, So PP, Poon PC and Au JS: The role of inflammation in the pathogenesis of lung cancer. Expert Opin Ther Targets 15: 1127-1237, 2011

54. Yang B, Chen D, Hui Z and Xiao C: The effects for PM2.5 exposure on non-small-cell lung cancer induced motility and proliferation. Springerplus 5: 2059, 2016.

55. Almatroodi SA, McDonald CF and Pouniotis DS: Alveolar macrophage polarisation in lung cancer. Lung Cancer Int 2014: 721087, 2014

56. Baulig A, Blanchet S, Rumelhard M, Lacroix G, Marano F and Baeza-Squiban A: Fine urban atmospheric particulate matter modulates inflammatory gene and protein expression in human bronchial epithelial cells. Front Biosci 12: 771-782, 2007.

57. Gualtieri M, Mantecca P, Cetta F and Camatini M: Organic compounds in tire particle induce reactive oxygen species and heat-shock proteins in the human alveolar cell line A549. Environ Int 34: 437-442, 2008.

58. Jiang M, Wei Q, Dong G, Komatsu M, Su Y and Dong Z Autophagy in proximal tubules protects against acute kidney injury. Kidney Int 82: 1271-1283, 2012.

59. Viry E, Paggetti J, Baginska J, Mgrditchian T, Berchem G, Moussay E and Janji B: Autophagy: An adaptive metabolic response to stress shaping the antitumor immunity. Biochem Pharmacol 92: 31-42, 2014

60. Taylor R, Cullen S and Martin S: Apoptosis: Controlled demolition at the cellular level. Nat Rev Mol Cell Biol 9: 231-241, 2008.

61. Kim R, Emi M and Tanabe K: Role of mitochondria as the gardens of cell death. Cancer Chemother Pharmacol 57: 545-553, 2006.

62. Mohseni N, McMillan S, Chaudhary R, Mok J and Reed B Autophagy promotes caspase-dependent cell death during Drosophila development. Autophagy 5: 329-338, 2009.

63. Joubert PE, Werneke SW, de la Calle C, Guivel-Benhassine F, Giodini A, Peduto L, Levine B, Schwartz O, Lenschow DJ and Albert ML: Chikungunya virus-induced autophagy delays caspase-dependent cell death. J Exp Med 209: 1029-1047, 2012.

64. You M, Savaraj N, Kuo MT, Wangpaichitr M, Varona-Santos J, Wu C, Nguyen DM and Feun L: TR AIL induces autophagic protein cleavage through caspase activation in melanoma cell lines under arginine deprivation. Mol Cell Biochem 374: 181-190, 2013.

65. Cho D, Jo Y, Hwang JJ, Lee YM, Roh SA and Kim JC: Caspase-mediated cleavage of ATG6/Beclin-1 links apoptosis to autophagy in HeLa cells. Cancer Lett 274: 95-100, 2009.

66. Hou W, Han J, Lu C, Goldstein LA and Rabinowich H: Autophagic degradation of active caspase-8: A crosstalk mechanism between autophagy and apoptosis. Autophagy 6: 891-900, 2010.

67. Xu X, Wang H, Liu S, Xing C, Liu Y, Aodengqimuge, Zhou W, Yuan X, Ma Y, Hu M, et al: TP53-dependent autophagy links the ATR-CHEK1 axis activation to proinflammatory VEGFA production in human bronchial epithelial cells exposed to fine particulate matter (PM2.5). Autophagy 12: 1832, 2016.

68. Liu T, Wu B, Wang Y, He H, Lin Z, Tan J, Yang L, Kamp DW, Zhou X, Tang J, et al: Particulate matter 2.5 induces autophagy via inhibition of the phosphatidylinositol3-kinase/Akt/mammalian target of rapamycin kinase signaling pathway in human bronchial epithelial cells. Mol Med Report 12: 1914-1922, 2015.

69. Wang Y, Lin Z, Huang H, He H, Yang L, Chen T, Yang T, Ren N, Jiang Y, Xu W, et al: AMPK is required for PM2.5-induced autophagy in human lung epithelial A549 cells. Int J Clin Exp Med 8: 58-72, 2015 . 
70. Zhou Z, Shao T, Qin M, Miao X, Chang Y, Sheng W, Wu F and Yu Y: The effects of autophagy on vascular endothelial cells induced by airborne PM2.5. J Environ Sci, 2017 (In Press).

71. Longhin E, Holme JA, Gutzkow KB, Arlt VM, Kucab JE, Camatini $\mathrm{M}$ and Gualtieri $\mathrm{M}$ : Cell cycle alterations induced by urban PM2.5 in bronchial epithelial cells: Characterization of the process and possible mechanisms involved. Part Fibre Toxicol 10: 63, 2013.

72. Gualtieri M, Ovrevik J, Mollerup S, Asare N, Longhin E, Dahlman HJ, Camatini $M$ and Holme JA: Airborne urban particles (Milan winter-PM2.5) cause mitotic arrest and cell death: Effects on DNA, mitochondria, AhR binding and spindle organization. Mutat Res 713: 18-31, 2011.

73. Abbas I, Verdin A, Escande F, Saint-Georges F, Cazier F, Mulliez P, Courcot D, Shirali P, Gosset P and Garçon G: In vitro short-term exposure to air pollution PM2.5-0.3 induced cell cycle alterations and genetic instability in a human lung cell coculture model. Environ Res 147: 146-158, 2016.

74. Deng X, Zhang F, Wang L, Rui W, Long F, Zhao Y, Chen D and Ding W: Airborne fine particulate matter induces multiple cel death pathways in human lung epithelial cells. Apoptosis 19: 1099-1112, 2014

75. Dagher Z, Garcon G, Billet S, Gosset P, Ledoux F, Courcot D, Aboukais A and Shirali P: Activation of different pathways of apoptosis by air pollution particulate matter (PM2.5) in human epithelial lung cells (L132) in culture. Toxicology 225: 12-24, 2006.

76. Ezegbunam W and Foronjy R: Posttranscriptional control of airway inflammation. Wiley Interdiscip Rev RNA 9: e1455, 2018.

77. Su N, Lin J, Chen P, Li J, Wu C, Yin K, Liu C, Chen Y, Zhou X and Yuan Y: Evaluation of asthma control and patient's perception of asthma: findings and analysis of a nationwide questionnaire-based survey in China. J Asthma 50: 861-870, 2013

78. Tecer LH, Alagha O, Karaca F, Tuncel G and Eldes N: Particulate matter (PM(2.5), PM(10-2.5), and PM(10)) and children's hospita admissions for asthma and respiratory diseases: A bidirectional case-crossover study. J Toxicol Environ Health A 71: 512-520, 2008.

79. Jalaludin B, Khalaj B, Sheppeard V and Morgan G: Air pollution and ED visits for asthma in Australian children: A case-crossover analysis. Int Arch Occup Environ Health 81: 967-974, 2008.

80. Jacquemin B, Siroux V, Sanchez M, Carsin AE, Schikowski T, Adam M, Bellisario V, Buschka A, Bono R, Brunekreef B, et al: Ambient air pollution and adult asthma incidence in six European cohorts (ESCAPE). Environ Health Perspect 123: 613-621, 2015.

81. Kim H, Kim H, Park YH and Lee JT: Assessment of temporal variation for the risk of particulate matters on asthma hospitalization. Environ Res 156: 542-550, 2017.

82. Yan C, Wong GW and Jing L: Environmental exposure and genetic predisposition as risk factors for Asthma in China. Allergy Asthma Immunol Res 8: 92-100, 2016.

83. Maestrelli P, Canova C, Scapellato ML, Visentin A, Tessari R, Bartolucci GB, Simonato L and Lotti M: Personal exposure to particulate matter is associated with worse health perception in adult asthma. J Investig Allergol Clin Immunol 21: 120-128, 2011.

84. Wagner JG, Morishita M, Keeler GJ and Harkema JR: Divergent effects of urban particulate air pollution on allergic airway responses in experimental asthma: A comparison of field exposure studies. Environ Health 11: 45, 2012

85. Xiang Z, Xu X, Zheng X, Reponen T, Chen A and Xia H: Heavy metals in PM 2.5 and in blood, and children's respiratory symptoms and asthma from an e-waste recycling area. Environ Pollut 210: 346-353, 2016.

86. Yao W, Wang C, Zhong N, Han X, Wu C, Yan X, Chen P, Yang W, Henley M and Kramer B: Effect of once-daily indacaterol in a predominantly Chinese population with chronic obstructive pulmonary disease: A 26-week Asia-Pacific study. Respirology 19: 231-238, 2014

87. Montoya-Estrada A, Torres-Ramos YD, Flores-Pliego A, Ramirez-Venegas A, Ceballos-Reyes GM, Guzman-Grenfell AM and Hicks JJ: Urban PM2.5 activates GAPDH and induces RBC damage in COPD patients. Front Biosci (Schol Ed) 5: 638-649, 2013.

88. Cortezlugo M, Ramírezaguilar M, Pérezpadilla R, Sansoresmartínez R, Ramírezvenegas A and Barrazavillarreal A: Effect of personal exposure to PM2.5 on respiratory health in a mexican panel of patients with COPD. Int J Environ Res Public Health 12: 10635-10647, 2015.
89. Rice MB, Ljungman PL, Wilker EH, Dorans KS, Gold DR Schwartz J, Koutrakis P, Washko GR, O'Connor GT and Mittleman MA: Long-term exposure to traffic emissions and fine particulate matter and lung function decline in the Framingham heart study. Am J Respir Crit Care Med 191: 656-664, 2015

90. Ren J, Li B, Yu D, Liu J and Ma Z: Approaches to prevent the patients with chronic airway diseases from exacerbation in the haze weather. J Thorac Dis 8: E1-E7, 2016.

91. Rahman I and Adcock I: Oxidative stress and redox regulation of lung inflammation in COPD. Eur Respir J 28: 219-242, 2006.

92. Watterson TL, Sorenson J, Martin R and Coulombe RA Jr: Effects of PM2.5 Collected from Cache Valley Utah in Human Bronchial Epithelial Cells. Annual Meeting of the Society of Toxicology, 2006.

93. Li R, Kou X, Xie L, Cheng F and Geng H: Effects of ambient PM2.5 on pathological injury, inflammation, oxidative stress, metabolic enzyme activity, and expression of c-fos and c-jun in lungs of rats. Environ Sci Pollut Res Int 22: 20167-20176, 2015.

94. Riva DR, Magalhães CB, Lopes AA, Lanças T, Mauad T, Malm O, Valença SS, Saldiva PH, Faffe DS and Zin WA: Low dose of fine particulate matter (PM2.5) can induce acute oxidative stress, inflammation and pulmonary impairment in healthy mice. Inhal Toxicol 23: 57-67, 2011.

95. Zhao QJ, Liu XJ, Zeng XL and Bao HR: Effect of PM2.5 on the level of nuclear factor erythroid-2 related factor 2 in chronic obstructive pulmonary disease mice and its relationship with oxidative stress. Zhonghua Yi Xue Za Zhi 96: 2241-2245, 2016 (In Chinese).

96. Yan Z, Wang J, Li J, Jiang N, Zhang R, Yang W, Yao W and $\mathrm{Wu} \mathrm{W}$ : Oxidative stress and endocytosis are involved in upregulation of interleukin-8 expression in airway cells exposed to PM2.5. Environ Toxicol 31: 1869-1878, 2016.

97. Xu D, Huang N, Wang Q and Liu H: Study of ambient PM2.5 on the influence of the inflammation injury and the immune function of subchronic exposure rats. Wei Sheng Yan Jiu 37: 423-428, 2008 (In Chinese).

98. Shu J, Liu X, Chu X, Qiu J, Zeng X and Bao H: Effects of PM2.5 on phagocytic function of alveolar macrophages in chronic obstructive pulmonary disease mice. Zhonghua Yi Xue Za Zhi 96: 301-305, 2016 (In Chinese)

99. Gu XY, Chu X, Zeng XL, Bao HR and Liu XJ: Effects of PM2.5 exposure on the Notch signaling pathway and immune imbalance in chronic obstructive pulmonary disease. Environ Pollut 226: 163-173, 2017.

100. Hong Z, Guo Z, Zhang R, Xu J, Dong W, Zhuang G and Deng C Airborne fine particulate matter induces oxidative stress and inflammation in human nasal epithelial cells. Tohoku J Exp Med 239: 117-125, 2016.

101. Bekki K, Ito T, Yoshida Y, He C, Arashidani K, He M, Sun G, Zeng Y, Sone H and Kunugita N: PM2.5 collected in China causes inflammatory and oxidative stress responses in macrophages through the multiple pathways. Environ Toxicol Pharmacol 45: 362-369, 2016.

102. Liu Q, Baumgartner J, Zhang Y, Liu Y, Sun Y and Zhang M: Oxidative potential and inflammatory impacts of source apportioned ambient air pollution in Beijing. Environ Sci Technol 48: 12920-12929, 2014

103. Zhang X, Zhong W, Meng Q, Lin Q, Fang C, Huang X, Li C, Huang Y and Tan J: Ambient PM2.5 exposure exacerbates severity of allergic asthma in previously sensitized mice. J Asthma 52: 785-794, 2015

104. Zhao C, Liao J, Chu W, Wang S, Yang T, Tao Y and Wang G: Involvement of TLR2 and TLR4 and Th1/Th2 shift in inflammatory responses induced by fine ambient particulate matter in mice. Inhal Toxicol 24: 918-927, 2012.

105. Huang KL, Liu SY, Chou CC, Lee YH and Cheng TJ: The effect of size-segregated ambient particulate matter on Th1/Th2-like immune responses in mice. PLoS One 12: e0173158, 2017.

106. Xie X, Chen J, Li F, Tian J, Gao JS and Zhang D: A T-cell-based enzyme-linked immunospot assay for tuberculosis screening in Chinese patients with rheumatic diseases receiving infliximab therapy. Clin Exp Med 11: 155-161, 2011

107. Jassal MS, Bakman I and Jones B: Correlation of ambient pollution levels and heavily-trafficked roadway proximity on the prevalence of smear-positive tuberculosis. Public Health 127: 268-274, 2013

108. Lai TC, Chiang CY, Wu CF, Yang SL, Liu DP, Chan CC and Lin HH: Ambient air pollution and risk of tuberculosis: A cohort study. Occup Environ Med 73: 56-61, 2016. 
109. Nicola I, Cerutti F, Grego E, Bertone I, Gianella P, D'Angelo A Peletto $\mathrm{S}$ and Bellino C: Characterization of the upper and lower respiratory tract microbiota in Piedmontese calves. Microbiome 5: 152, 2017.

110. Rivas-Santiago CE,Sarkar S, Cantarella P IV, Osornio-Vargas Á, Quintana-Belmares R, Meng Q, Kirn TJ, Ohman Strickland P, Chow JC, Watson JG, et al: Air pollution particulate matter alters antimycobacterial respiratory epithelium innate immunity. Infect Immun 83: 2507-2517, 2015.

111. MacIntyre EA, Gehring U, Mölter A, Fuertes E, Klümper C, Krämer U, Quass U,Hoffmann B, Gascon M, Brunekreef B, et al: Air pollution and respiratory infections during early childhood: An analysis of 10 European birth cohorts within the ESCAPE Project. Environ Health Perspect 122: 107-113, 2014.
112. Darrow LA, Klein M, Flanders WD, Mulholland JA, Tolbert PE and Strickland MJ: Air pollution and acute respiratory infections among children 0-4 years of age: An 18-year time-series study. Am J Epidemiol 180: 968-977, 2014.

113. Ghosh R, Rossner P, Honkova K, Dostal M, Sram RJ and Hertzpicciotto I: Air pollution and childhood bronchitis: Interaction with xenobiotic, immune regulatory and DNA repair genes. Environ Int 87: 94-100, 2016. 